\title{
A PRODUÇÃO DE CONHECIMENTO NA FORMAÇÃO DE PROFESSORES: UMA CONDIÇÃO INDISPENSÁVEL
}

\section{LA PRODUCCIÓN DE CONOCIMIENTO EN LA FORMACIÓN DEL PROFESORADO: UNA CONDICIÓN INDISPENSABLE}

\author{
Marco Aurelio Cardoso Moura
}

\begin{abstract}
RESUMO: Este artigo tem o objetivo de pensar o papel que a nova Base Nacional Comum Curricular (BNCC) propõe para a atuação docente, a saber: o de professor mediador. Analisamos especificamente a orientação da lei $n^{\circ}$ 13.415/2017 quanto à aplicação de metodologias diversificadas como método de trabalho na sala de aula. A hipótese é de que, mediante o atual retrato da formação de professores, é provável que essa orientação específica possa encontrar dificuldades de ser efetivada de forma satisfatória. Metodologicamente, partimos do estudo de autores de manuais pedagógicos que foram professores do ensino secundário dos anos 1930 a 1960. A pesquisa sobre a trajetória desses professores nos levou ao estudo da história da institucionalização da formação docente, além das legislações educacionais de diferentes períodos. Tudo isso contribuiu para a construção de um retrato da formação docente por meio do Censo do Ensino Superior de 2019, realizado pelo INEP. Assim, concluímos que as marcas da divisão entre os professores que produzem conhecimento e aqueles que os transmitem se mantém na formação docente atualmente. Essa distância das metodologias cientificas pode comprometer o desempenho dos professores em sala de aula, bem como na aplicação de metodologias diversificadas, como orienta a nova BNCC.
\end{abstract}

Palavras-chave: Formação de professores. Ensino médio, Nova BNCC.

RESUMEN: Este trabajo tiene como objetivo pensar en el papel que la nueva Base Nacional Común Curricular (BNCC) indica para el trabajo del docente, el papel de profesor mediador. Específicamente, analizamos la orientación de la ley no 13.415/2017 sobre la aplicación de metodologías diversificadas como método de trabajo en la escuela. La hipótesis es que, dado el retrato actual de la formación docente, es probable que esta orientación específica puede encontrar dificultades para ser implementada satisfactoriamente. Metodológicamente, partimos del estudio de los autores de manuales pedagógicos que fueron profesores de escuela secundaria desde los años 1930 hasta los años 1960. La investigación sobre la trayectoria de estos docentes nos llevó a estudiar la historia de la institucionalización de la formación docente, además de la legislación educativa de tiempos distintos. Esto contribuyó a la construcción de un retrato de la formación del profesorado a través del Censo do Ensino Superior en 2019, realizado por INEP. Así, concluimos que las marcas de la división entre los profesores que producen conocimiento y los que lo transmiten permanecen en la formación del profesor hoy. Este alejamiento de las metodologías científicas puede comprometer el desempeño de los docentes en el aula, así como en la aplicación de metodologías diversificadas, guiadas por la nueva BNNC.

Keywords: Formación docente. Educación básica. Nueva BNCC.

\section{Introdução}

Este artigo é um estudo que tem por objetivo pensar o papel que a nova Base Nacional Comum Curricular (BNCC) propõe para a atuação docente, a saber: o de

\footnotetext{
1 Universidade de São Paulo, Brasil. E-mail: marco.aurelio.moura@usp.br

(iD) https://orcid.org/0000-0002-9146-848X

- Informações completas da obra no final do artigo
} 
professor mediador. Analisamos especificamente a orientação da lei № 13.415/2017 quanto à aplicação de metodologias diversificadas como método de trabalho na sala de aula. $A$ hipótese é de que, mediante o atual retrato da formação de professores, é provável que essa orientação específica pode encontrar dificuldades de ser efetivada de forma satisfatória. O estudo se torna relevante a medida em que a perspectiva histórica revela que o processo de institucionalização da formação dos professores foi sendo gradualmente precarizado, ocorrendo uma perda significativa do protagonismo docente.

Para tanto, iniciamos o texto resgatando o perfil docente de nível secundário dos anos de 1930 a 1960. Esse caminho foi guiado pela diferença entre o professor produtor de conhecimentos e o professor que os transmite (GERALDI, 2013; FREIRE, 2020). Essa separação pode ser vista como uma característica importante que marca a formação de professores até os dias de hoje. A metodologia se baseou na pesquisa de manuais pedagógicos, com ênfase no estudo dos autores desses manuais e de que forma esse artefato da cultura pedagógica impactou os professores em formação. Nesse sentido, a análise de documentação histórica e das legislações educacionais ocupou parte importante deste artigo.

O artigo percorre o seguinte caminho: primeiramente abordamos a problemática da separação do professor produtor e transmissor de conhecimentos e os fatores que provocaram esse fenômeno; em seguida, percorreremos a trajetória dos professores Antenor Nascentes (1886-1972) e Leodegário Amarantes do Azevedo Filho (1927-2011), ambos lecionaram língua portuguesa no curso secundário do Colégio Pedro II e foram autores, respectivamente, dos manuais Idioma Nacional na escola secundária, de 1935, e Didática Especial de Português para o curso secundário, de 1958. A pesquisa a respeito da formação docente atualmente foi feita pela leitura e análise dos dados do Censo do Ensino Superior de 2019, realizado pelo INEP. Por fim, analisamos a nova BNCC, especificamente sua orientação para aplicação de metodologias diversificadas e o papel do professor enquanto mediador entre os saberes a serem ensinados e os estudantes, em contraste com o retrato da formação de professores.

A nova BNCC pretende oferecer diretrizes que visam contribuir com o trabalho docente a fim de, entre outros objetivos, modernizar as práticas pedagógicas. Contudo, as condições que os professores chegam nas escolas precisam acompanhar essa modernização. Esse artigo pretende contribuir com apontamentos modestos nessa direção. 


\section{O professor entre dois mundos}

A divisão entre trabalho intelectual e braçal é uma realidade que se impõe em todos os setores produtivos. Na educação não é diferente e o professor, à medida que o sistema capitalista foi se tornando hegemônico, passou a ocupar um lugar híbrido nessa relação. Como descreve Geraldi (2013):

Qual o significado, no Trezentos e no Quatrocentos, da existência de tais mestres?
[...]. Nestas, o professor pago ou não por seus alunos, pela comunidade ou
sustentado pela abadia, se caracteriza ou se identifica pelo fato de ser um produtor
de conhecimentos, produtor de um saber, de uma reflexão. E como tal fala sobre
este saber a discípulos (ou mesmo seguidores). [...]. Nos primórdios do
mercantilismo vamos encontrar já uma divisão social do trabalho responsável pelo
surgimento de uma nova identidade: o mestre já não se constitui pelo saber que
produz, mas por saber um saber produzido que ele transmite. (GERALDI, 2013, p.
86-87).

Apesar de Geraldi (2013) localizar as mudanças na atividade docente a partir do período do mercantilismo, a educação, fora dos ambientes religiosos no Brasil, é tardia. Diante disso, os professores que atuavam no ensino secundário, a partir do século XIX, eram responsáveis por construir e organizar os conteúdos que seriam transmitidos na escola ou usavam os raros materiais pedagógicos disponíveis nas províncias.

Posteriormente, ao assumir o papel de transmissor de um conhecimento previamente estabelecido e sistematizado, o professor se torna operador de uma tarefa de caráter repetitivo. "O trabalho do professor aproxima-se, em termos técnicos, cada vez mais do trabalho manual" (GERALDI, 2013, p. 95). Essa característica fragiliza socialmente a posição do professor em uma sociedade que privilegia o trabalho intelectual. Na medida em que o exercício do magistério exige cada vez menos qualificação para ser executado, a educação passa por um processo de desprestígio e desvalorização.

Do ponto de vista da formação docente, o professor, distante da produção de conhecimento na disciplina que leciona, necessita incluir, em seu itinerário de trabalho, a tarefa de estar constantemente atualizado nas pesquisas de sua área de conhecimento. No entanto, mesmo que este profissional faça um esforço para se manter atualizado, muitas vezes sem o apoio institucional do Estado, ele estará sempre um passo atrás e terá de lidar com os desafios de aplicação desses novos saberes na sala de aula. 
Quando novidades de pesquisa chegam à escola não é porque "agora tudo mudou" ou porque "o que se pensava antes estava errado" e é preciso "embarcar na nova onda". É preciso afastar essa ingenuidade. É preciso entender que iluminações novas são consequências de definições novas do objeto de estudos. Nesse sentido, cumpre afastar duas formas de fetichizações: compreender o novo como mera "novidade" e pensar que este novo é definitivo, que agora sim chegou-se a um ponto ômega, a um ponto final de investigação. Esta segunda fetichização é uma das responsáveis por certas afirmações ingênuas de professores "pessimistas" que, ao final ou quase ao final da carreira, acabam reagindo a qualquer mudança porque "viram muitas mudanças na vida" e elas nada significaram de concreto na melhoria do ensino. Trata-se de uma espécie de saudosismo, mas saudosismo que não é só do passado; é fundamentalmente um saudosismo da estabilidade, da fixidez, o que revela uma incompreensão do processo de fazer ciência. (GERALDI, 2013, p. 84).

Esse processo de baixa participação do professor nos avanços científicos de sua área de conhecimento, expresso pelo excerto acima, provoca importantes consequências para o ensino, sobretudo na atualidade da nova BNCC. Como garantir um processo mais horizontal de ensino, com protagonismo dos alunos, sem um devido preparo dos professores para essa tarefa?

Essa característica da formação dos professores é resultado de um processo histórico gradual abordado e apresentado nos tópicos a seguir. Por eles vamos observar a institucionalização da docência e suas trajetórias de formação.

\section{Os professores nos trópicos}

O sistema educacional no Brasil se manteve monopolizado nas mãos da Companhia de Jesus até a sua expulsão pelo Marquês de Pombal em 1759. Dessa forma, não havia instituições estatais para a formação de professores que atendessem às novas orientações assumidas pelo iluminismo pombalino. A solução, provisória e improvisada, se deu, como descreve Fávero (2002):

Quanto ao ensino secundário, havia a proliferação de aulas avulsas e particulares, continuando o sistema das aulas régias inaugurado por Pombal no século XVIII, deviam chegar a cem e consistiam no ensino do latim, comércio, geometria, francês, retórica e filosofia e foram diminuindo com o tempo até sua extinção em 1857, por não tratarem de todas as disciplinas necessárias aos exames preparatórios, por haver dificuldades por parte dos alunos de se deslocarem de uma residência do professor à outra, acabando por serem procuradas só por aqueles que, embora não tendo condições de ingressarem no ensino superior, queriam instruir-se. Assim, bem ou mal, as aulas avulsas prestavam serviço aos alunos menos aquinhoados economicamente. (FÁVERO, 2002, p.68, grifo nosso).

O excerto de Fávero (2002) apresenta o contexto para o ensino secundário, enquanto que o ensino primário ainda era praticamente inexistente. Segundo Saviani (2019) é somente com a Constituição de 1824, outorgada por Dom Pedro I, que é determinado 
que: "a instrução primária é gratuita a todos os cidadãos". Entretanto, é transferida a responsabilidade pela oferta de educação a cada província, sem nenhuma política pública proveniente da coroa.

No que diz respeito à formação do professor para o nível primário, as províncias adotam o modelo das Escolas Normais. Assim descreve Saviani (2012):

A promulgação do Ato Adicional de 1834, que colocou a instrução primária sob a responsabilidade das províncias, estas tenderam a adotar, para a formação de professores, a via que vinha sendo seguida nos países europeus: a criação de Escolas Normais. (SAVIANI, 2012, p. 12).

A primeira Escola Normal data de 1835 em Niterói no Rio de Janeiro. Desde esse marco, essas instituições passaram por muitas dificuldades para continuar existindo. Quase sempre suas estruturas físicas eram precárias e ocupavam prédios cedidos pela igreja católica. Além disso, a instrução oferecida aos professores era bastante rudimentar, por muito tempo sem um preparo pedagógico específico para o exercício do magistério. (TANURI, 2000; SAVIANI, 2019).

Ademais, a oferta de ensino primário se mantinha bastante baixa e o incentivo para o exercício do magistério não era grande. No que diz respeito ao nível secundário, este passa a ter um novo status com a fundação do imperial Colégio de Pedro II em 1837.

A principal preocupação do governo durante a primeira metade do século XIX era a formação da elite dirigente, o que levou a concentrar seus esforços no ensino superior e secundário, não tendo realizado quase nada em relação ao primário e ao técnico-comercial. (FÁVERO, 2002, p.66).

Essa característica elitista que assume o ensino secundário será determinante para a formação do perfil dos candidatos ao magistério para este nível do ensino. Como dissemos anteriormente, as Escolas Normais foram direcionadas exclusivamente à formação de professores para o nível primário, assim sendo, os professores de nível secundário estudavam nas recém-criadas faculdades de direito, engenharia e medicina ${ }^{2}$, nos institutos militares ${ }^{3}$ ou eram provenientes do clero.

\footnotetext{
2 "A partir de 1828 iniciavam-se os primeiros cursos [de direito e medicina], e de forma ascendente a profissão e a figura do bacharel tornavam-se estimuladas no Brasil". (SCHWARCZ, 1993, p. 186).

3 "(...) Em 1810, com a Artilharia e Fortificação, foi criada a Academia Militar a fim de garantir o ensino das ciências matemáticas, física, química, história natural, técnicas de guerra, fortificação e defesas". (SCHWARCZ, 2002, p. 256).
} 
Ademais, a carreira docente funcionava por uma lógica bastante clientelista. Assim afirma Vilela (2014):

No Brasil do século XIX, o provimento de cargos no magistério mobilizava um complexo sistema de concessão ou intermediação de favores, em que o emprego público ocupava lugar central. Relações clientelísticas amarravam o sistema social e político de alto a baixo, como observou Richard Grahan (1997), definindo redes de lealdades baseadas em laços de família, amizade e proteção. (VILELA, 2014, p.112).

Essas relações, que os candidatos ao magistério se utilizavam para ingressar nos cargos disponíveis, não os eximiam de prestar um concurso no qual deveriam apresentar um trabalho original sobre algum objeto da disciplina que pretendiam lecionar. Esse trabalho era defendido perante uma banca que avaliava a qualificação do candidato mediante este processo. A produção dessa pesquisa obrigava os candidatos a dominar os métodos e técnicas de pesquisa disponíveis em seu tempo.

Observamos, mais adiante, que a mudança desse perfil de professor-intelectual não necessariamente "pesquisador", porque provavelmente não era essa a noção suposta na época - autor de manual didático constrói-se na interface com a perspectiva clássicabeletrista do próprio ensino: é com a Lei no 9.394/96, com o tecnicismo pedagógico nela suposto, que o perfil de professor-intelectual-autor de manual se esvai, dando lugar ao professor como peça na engrenagem da escola usina.

Para demonstrar como a junção entre pesquisa e ensino acontecia no nível secundário, abordamos a seguir, a trajetória de dois professores de língua portuguesa do Colégio Pedro II: Antenor Nascentes (1886-1972) e Leodegário Amarantes do Azevedo Filho (1927-2011).

\section{Professor Antenor Nascentes}

Antenor de Veras Nascentes nasceu em 19 de junho de 1886 no Rio de Janeiro. Ele foi um importante professor, filólogo, etimólogo, dialetólogo, e lexicógrafo brasileiro. A formação do professor Antenor Nascentes não foge à regra dos demais mestre-escola do período. Diplomado em direito, ou em outras áreas liberais, o candidato ao magistério acabava por atingir um repertório cultural, histórico e linguístico muito acima da média 
adquirida pela população ${ }^{4}$. Isso permitia que o bacharel se preparasse, muitas vezes de forma autônoma e autodidata, para os concursos do magistério secundário.

Em certa altura, Nascentes faz um relato curioso sobre sua trajetória:

A obra consumiu-lhe vários anos da sua vida. Com razão, pois, pode dizer, comentando a sua transferência para a cadeira de Português no Colégio Pedro II: "Minha transferência para português, sem concurso, deu que falar. - Respondo a estes murmuradores com a publicação do Dicionário Etimológico. O dicionário valeu por um concurso". (Discurso -proferido em 23 de setembro de 1952 no salão nobre do Externato do Colégio Pedro II por ocasião do recebimento do título de professor emérito, Rio, 1952, p. 13). (HAMPEJS, 1961, p. 6)

Por esse breve relato é possível observar o peso que a produção acadêmica do candidato ao magistério tinha no período. Contudo, isso não anula, particularmente, uma percepção importante que Antenor Nascentes expressará em uma de suas obras. Essa percepção diz respeito ao fato de o professor de nível secundário não necessitar, àquela altura, de nenhum preparo didático ou metodológico ampara o exercício da profissão. Em sua obra O idioma nacional na escola secundária, publicado em 1935, afirma o autor: "Nossos governos tardaram em criar uma escola normal superior, de modo que neste vasto país de quarenta milhões de almas os professores secundários ainda são uns auto-didatas". (NASCENTES, 1935, p. 11). Provocado pelas reflexões do movimento da Escola Nova, ${ }^{5}$ Nascente avalia que os professores secundários são "autodidatas" e que se faz necessária uma formação especifica para este grupo.

Em 1952, Antenor Nascentes recebe o título de professor emérito do Colégio Pedro II e, nessa altura, já ocupa o posto de professor universitário na cátedra de Filologia Românica da Faculdade de Filosofia, Ciências e Letras da Universidade do Rio de Janeiro. Contudo, independentemente de seu vínculo com a universidade, Nascentes já contava com uma vasta produção acadêmica na área de filologia e língua portuguesa. Destacam-

\footnotetext{
${ }^{4} \mathrm{O}$ grau de instrução que atingia o bacharel era superior inclusive ao que obtinha aqueles formados pelas Escolas Normais: "Via de regra, as escolas normais não alcançavam ainda o nível do curso secundário, sendo inferiores a este quer no conteúdo, quer na duração dos estudos". (TANURI, 2000, p. 67).

5 "Pedagogia escolanovista" ou "Pedagogia da Escola Nova" é uma denominação referida ao amplo movimento de contraposição à pedagogia tradicional que se desenvolveu a partir do final do século XIX e se estendeu ao longo do século XX. (...). Abarca um conjunto grande de autores e correntes que têm em comum a ideia de que a criança, e não o professor, é o centro do processo educativo, devendo, pois, o ensino ter como móvel principal a atividade e os interesses das crianças, vistas como sujeitos de sua própria aprendizagem". (SAVIANI, 2012, p.155).
} 
se: O linguajar Carioca de 1922; O idioma nacional em quatro volumes de 1926 a 1928 e Dicionário etimológico da língua portuguesa de 1932.

A produção acadêmica de Antenor Nascentes é vastíssima e, certamente, sustenta o respeito que este mestre assumiu na cena intelectual brasileira. Sua vida longa, faleceu em 1972 aos 86 anos, Ihe proporcionou condições para desenvolver muitos trabalhos e seu vínculo com a universidade foi fundamental para atingir tais resultados. Todavia, é importante destacar que sua trajetória junto ao nível secundário impactou profundamente seu olhar sobre o ensino da língua portuguesa.

\section{Professor Leodegário Azevedo Filho}

Leodegário Amarante do Azevedo Filho nasceu na cidade do Recife em 1927. Ainda jovem, mudou-se para o Rio de Janeiro onde estudou no Colégio Pedro II, obtendo o grau de bacharel em ciências e letras concedido, à época, aos que se formavam nessa instituição. Graduou-se em direito pela UERJ e obteve seu doutorado em letras pela mesma universidade.

Segundo relato da professora llka Souza Lima de Azevedo, esposa de Leodegário, este, desde cedo, conviveu com figuras que simbolizam bastante o perfil de professor que buscamos nos aproximar neste artigo:

Depois de cursar o antigo Curso Primário, ingressa, pelas mãos generosas do
reconhecido Mestre Clóvis Monteiro, no Internato do Colégio Pedro II, na época
considerado padrão para o ensino secundário brasileiro. E lá permanece por 7 anos,
conquistando seu primeiro diploma: o Diploma de Bacharel em Ciências e Letras,
no ano de 1947 . Por ali passaram eminências do nosso Magistério e Leodegário
teve a sorte de receber ensinamentos de Mestres, cujos nomes costumava citar
com muito orgulho: Antenor Nascentes, Silva Ramos, Said Ali, José Oiticica,
Quintino do Valle, Fernando Barata, Aldemir S. Paulo, Newton Maia, Godofredo
Ferreira, Saboia Barbosa, George Sumner, Hilda Reis, Curvelo de Mendonça, entre
outros, que marcaram definitivamente sua vida futura. (AZEVEDO, 2011, p. 12, grifo
nosso).

O registro de que Leodegário fora professor no Colégio Pedro II, no Colégio Andrews e no Ginásio Guido de Fontgalland consta na edição de seu manual Didática Especial de Português publicado em 1958. Nas palavras de llka, nos idos de 1961, Leodegário já ocupava cargo na UERJ. Logo, é provável que sua permanência nos colégios secundários tenha sido breve. 
Contudo, as primeiras produções acadêmicas do professor Leodegário datam da década de 1950, quando ainda era professor do ensino secundário. Esse fato marca inclusive a temática de seus primeiros escritos, sendo estes o manual já citado e Alguns problemas do idioma de 1953. Um ponto importante é que, diferente da obra que marca a trajetória de Leodegário enquanto filólogo, essas publicações têm uma preocupação direta com o ensino. Esse recorte evidencia a preocupação do autor envolvido diretamente com o exercício do magistério.

O envolvimento do mestre com a educação básica aparece também nas palavras de outro de seus admiradores:

Como dissemos, Leodegário foi, antes de tudo, um senhor professor, vocação que
se projeta em suas obras de cunho pedagógico, como sua Didática especial de
Português (RJ, 1958). Em 1959, editou a plaquete A educação de adultos no Distrito
Federal, seu discurso no Teatro João Caetano, como paraninfo de todas as turmas
dos cursos ginasiais e comerciais básicos do Departamento de Educação da
Prefeitura do nosso então Distrito Federal. (ARAÚJO, 2011, p. 10, grifo nosso).

A formação do professor Leodegário, todavia, seguiu a mesma regra dos demais professores secundários do período. Distante das Escolas Normais, os bacharéis, em diferentes profissões liberais, se "aventuravam" no ensino das disciplinas do currículo, por meio da tradicional transmissão de saberes, amparados por rígidos códigos de disciplina e contando com um repertório prévio de sua clientela escolar. Isso significa que o responsável por um eventual fracasso escolar era exclusivamente o aluno.

No caso do professor Leodegário, a preocupação com a didática do ensino acontece por sua aproximação com o ideário escolanovista. Esse repertório pedagógico aparece em seu manual, promovendo uma aplicação de metodologias de ensino à disciplina de língua portuguesa. Esse exercício também ocorreu com outras disciplinas curriculares. (NONATO, 2019).

É importante ressaltar que, ao trazer os exemplos dos professores Antenor Nascentes e Leodegário Azevedo Filho, não estamos fazendo uma apologia à organização escolar do ensino secundário do período, de evidente caráter elitista, mas chamamos atenção para as condições dadas aos professores para que pudessem produzir conhecimento durante o exercício do magistério ${ }^{6}$.

\footnotetext{
${ }^{6} \mathrm{O}$ professor-intelectual-autor de manual pedagógico representa um grupo que se encontra na transição das estruturas universitárias do país. Herdeiros de instituições regidas no modelo do século XIX, esses
} 
A questão que discutimos a seguir, são os fatores estruturais que levaram o professor a uma distância cada vez maior da produção de conhecimento e, com isso, ficar mais próximo de um trabalho "manual" e desvalorizado.

\section{A formação sob tutela}

Quando olhamos para a história da educação, pelo menos desde que se tornou reponsabilidade do Estado em fins do século XVIII, e para a formação dos professores, constatamos que a produção de conhecimento em educação quase sempre é realizada por pesquisadores que não atuam no ensino básico ${ }^{7}$. Os exemplos que trouxemos neste trabalho tratam de um segmento especifico e bastante elitizado do ensino, no caso o nível secundário, até pelo menos os anos de 1970.

Notamos que as bases teóricas presentes nas Escolas Normais, desde fins do século XIX, trazem uma bibliografia de base europeia e norte americana em áreas de influências nos estudos pedagógicos ${ }^{8}$. Todavia, a área da educação passará a ter uma preocupação com a produção de conhecimentos a partir dos anos 1930:

A década de 1930 representou um marco importante na história dessa instituição, quando houve reformar em vários estados cujo intuito foi imprimir nos cursos um caráter menos propedêutico e mais profissionalizante (Tanuri, 1969). Também nessa década a produção de manuais no país cresceu, pois até os anos 1920 circularam no país obras que, em sua maioria, foram assinadas por autores estrangeiros, sobretudo portugueses e franceses. (SILVA, 2019, p. 30).

\footnotetext{
professores são impactados pela criação das universidades, a partir dos anos de 1930, e vão aderir às ideias modernas vindas do campo pedagógico.

${ }^{7}$ Essa reflexão parte de uma observação mais intuitiva e comparativa. Quando olhamos para outras áreas do conhecimento como medicina, direito ou astronomia, os responsáveis por produzir o conhecimento nessas áreas são necessariamente profissionais diretamente envolvidos com esses campos de atuação. Entretanto, isso é visto numa escala muito reduzida na educação. Certamente, muitos professores universitários, responsáveis por produzir conhecimento na área da educação, atuaram no ensino básico, mas isso não é uma regra. Além disso, áreas afins como psicologia, medicina ou economia, que impactam profundamente as diretrizes educacionais, não contam com profissionais que atuaram na sala de aula do ensino básico. Assim, os professores acabam por ocupar um espaço secundário em sua própria área de trabalho.

8 "Apenas depois dos pareceres de Rui Barbosa, a bibliografia pedagógica brasileira entra numa fase mais fértil. Assim, em 1882 surgem os pareceres sobre as diversas questões do temário do não realizado Congresso de Instrução do Rio de Janeiro. Em 1884, edita-se o volume Lições de Coisas, de Saffray, e, em 1886, Primeiras Lições de Coisas, de Calkins, traduzido por Rui Barbosa, difundindo no Brasil as ideias de Pestalozzi e Froebel acerca do ensino intuitivo e da educação pelos sentidos, em oposição aos processos verbalistas da escola tradicional. Em 1887, é lançada a obra Pedagogia e Metodologia, do professor da Escola Normal de São Paulo Camilo Passalacqua e, no ano seguinte, o Tratado de Metodologia Coordenada, de Felisberto Rodrigues Pereira de Carvalho". (TANURI, 2000, p. 67).
} 
Os manuais pedagógicos de formação de professores são um objeto importantes de reflexão nessa análise, pois ocupam um espaço privilegiado na organização, síntese e transmissão de conhecimentos entendidos como essenciais para os candidatos ao magistério nesse período.

Por ora, convém atentar para o fato de que esses impressos tinham como tema principal a Escola Nova, enfatizando as finalidades da educação, conhecimentos sobre o desenvolvimento infantil e a descrição de experiências escolares consideradas "renovadas" e encaminhadas em diversos países. E, entre as áreas de saber mais referidas, estavam a psicologia, a pedagogia, a filosofia e a didática, tal como foi possível averiguar a partir de uma sistematização do conteúdo dos livros. (SILVA, 2019, p.65).

Os livros em geral, e os manuais de forma mais acentuada, possuem uma ordem que direciona a leitura a partir das intenções de seus autores e, sobretudo, editores. (CHARTIER, 1998). Os intelectuais responsáveis por produzir, traduzir, sistematizar e sintetizar os conteúdos presentes nos manuais pedagógicos compartilhavam, em sua maioria, um olhar depreciativo para com os estudantes das Escolas Normais:

Em geral, os responsáveis pelo material supunham ser os normalistas pouco hábeis na leitura ou um público "menos competente" nessa atividade, necessitando de dispositivos 'facilitadores', tais como constantes divisões do pensamento, ilustrações, esquemas explicativos, exercícios de fixação etc. A chamada "materialidade" dos livros também delimitou uma forma de manejo deles". (SILVA, 2019, p.52).

A partir do estudo de Silva (2019), é possível observar que o perfil dos autores desses manuais reforça a distância que ocupavam das salas de aula do ensino público primário, para o qual a maior parte desses materiais era destinado. "Quando houve o aumento dos impressos em questão, nos anos 1930, a maioria dos autores ocupava postos privilegiados na carreira do magistério". (SILVA, 2019, p. 188). ${ }^{9}$ Reconhecemos, contudo, que os estudantes de Escolas Normais não tinham formação suficiente para protagonizar esse papel, porém não houve, por sua vez, iniciativas que os preparassem para tal exercício.

Desta forma, a formação de professores para o nível primário seguiu um caminho bastante descontínuo e atribulado em suas políticas e organização. (TANURI, 2000;

\footnotetext{
${ }^{9}$ Essa análise não pretende diminuir a importância dos impressos pedagógicos destinados à formação de professores. Reconhecemos a importância dessas iniciativas para a alinhar a educação brasileira às pedagogias modernas dos países desenvolvidos. Contudo, identificamos que esses manuais geraram uma "tutela intelectual" nos estudantes do magistério, Ihes proporcionando pouco espaço para o exercício da produção de conhecimento baseado em suas próprias experiências e realidade locais.
} 
SAVIANI, 2012). Quanto à formação de professores para o nível secundário, sua estrutura sofre uma alteração importante a partir dos anos de 1930:

\begin{abstract}
Assim, desde o início do século $X X$, foram desenvolvidos cursos pós-normais, instalados junto à Escola Normal da Praça, em São Paulo, com o objetivo de promover o aperfeiçoamento de professores. Esses cursos foram a origem dos cursos superiores de formação do professor secundário implantados pela reforma Francisco Campos em 1931. [...]. [O Instituto Pedagógico de São Paulo] mais tarde, em 1933, foi transformado em Instituto de Educação Caetano de Campos, que passou a também formar os professores para o nível secundário e desenvolver pesquisas na área. Foi essa instituição que, em 1933, tornou-se o Instituto de Educação, depois incorporado à Universidade de São Paulo (USP), onde veio a ser uma unidade universitária de preparação de professores para todos os graus de ensino. (BAZZO, 2004, p. 271).
\end{abstract}

Além da formação de professores, a oferta de ensino secundário também passou por mudanças importantes. Francisco Campos, autor da reforma de ensino de Minas Gerais nos anos de 1927/28 (BICCAS, 2011, p.155-176), foi nomeado ministro da Educação e Saúde Pública pelo governo provisório de Getúlio Vargas. Como ministro, outorga o decreto no 19.890 de 18 de abril de 1931 que regerá o ensino secundário até novo decreto em $1942^{10}$.

Com o Decreto-Lei no 19.852/31 que institui a Faculdade de Educação Ciências e Letras, o então ministro Campos reconhece que há no Brasil: "um ensino sem professores, isto é, em que os professores criam a si mesmos, e toda a nossa cultura é puramente autodidática". (SAVIANI, 2012, p. 18). Todavia, a resistência à implementação dessa lei foi grande e, somente em 1939, na gestão Capanema no ministério da educação, é que o Decreto-Lei oㅗ 1.190/39, que vai vigorar até a reforma universitário de 1968, instituirá a Faculdade Nacional de Filosofia. Segundo Saviani (2012), será esse modelo responsável pela separação entre profissional que atuará no ensino secundário e o cientista.

Apesar de a demanda pelo ensino secundário permanecer baixa, a necessidade de preparar os professores levou à criação da Campanha de Aperfeiçoamento e Difusão do

\footnotetext{
10 O ensino secundário passa por outras mudanças legislativas. Em 1942 é instituído o decreto 4244. Está Lei dividia essa etapa da educação em duas partes: ginasial e colegial. O ginásio corresponde ao atual nível fundamental II e o colégio ao ensino médio que, por sua vez, se dividia em clássico e cientifico. Em todas essas etapas se exigia exame de admissão. O ensino secundário passará pelas mudanças da LDB $n^{\circ}$ 4.024/1961 que garantiu a equivalência plena entre o ensino secundário profissional e aquele que preparava para o ensino superior. (SAVIANI, 2019, p. 307). "Com a aprovação da Lei n 5692 . De 11 de agosto de 1971, buscou-se estender essa tendência produtivista a todas as escolas do país, por meio da pedagogia tecnicista, convertida em pedagogia oficial". (SAVIANI, 2019, p. 365). Consta-se ainda as mudanças da LDB 9.304/1996.
} 
Ensino Secundário (CADES) em 1953 ${ }^{11}$. Essa iniciativa teve um impacto considerável em termos de expansão da oferta de formação de professores. Nesse sentido, há um relato bastante interessante de um aluno do professor Leodegário:

\begin{abstract}
Como a minha Faculdade ainda não recebera a autorização definitiva do MEC para seu funcionamento pleno, resolvi inscrever-me no curso promovido pela Campanha de Aperfeiçoamento e Difusão do Ensino Secundário (CADES) naquele mês e ano, a fim de conseguir logo a autorização para lecionar no primeiro e segundo graus de ensino da época. O professor de conteúdo de Língua Portuguesa foi o cearense Otávio Faria que militava no ensino superior de Fortaleza; o de Didática da Língua Portuguesa foi o professor Leodegário. (ARAÚJO, 2011, p. 9).
\end{abstract}

Como expõe o depoimento acima, as faculdades ainda estavam em processo de implementação e a conjuntura política, sobretudo com a ruptura democrática do golpe civilmilitar de 1964, apresenta ainda mais desafios para a construção de um projeto educacional mais amplo e contínuo. Os impactos mais diretos, na formação de professores, se deram pela reforma universitária, Lei oㅜ 93.762 em 1968 e pela LDB ํㅜ 5.692/1971. O teor mais tecnicista que vigorou nesse período distanciou ainda mais os professores em formação de um aprofundamento teórico e crítico sobre educação durante sua formação e, evidentemente, em seu trabalho.

Os anos de 1980 marcaram os debates sobre a redemocratização do Brasil que se concretizaria, pelo menos em teoria, pela promulgação da Constituinte em 1988. A partir disso se intensificaram os debates por uma nova Lei de Diretrizes e Bases para a educação do país. Com isso, em 1996 foi promulgada a Lei no 9.394, a nova LDB. Essa nova legislação prometeu impactar bastante a formação de professores tornando obrigatório o curso superior para atuação em todo o ensino fundamental II e médio.

Nesse quadro referencial, a nova Lei de Diretrizes e Bases (Lei no 9.394/96) estabelece que "a formação de docentes para atuar na educação básica far-se-á em nível superior, em curso de licenciatura, de graduação plena, em universidades e institutos superiores de educação admitida, como formação mínima para o exercício do magistério na educação infantil e nos 5 (cinco) primeiros anos do ensino fundamental, a oferecida em nível médio na modalidade normal. (TANURI, 2002, p. 85).

\footnotetext{
11 "Para suprir a defasagem quanto à formação acadêmica dos professores, em 1953, é criada a Campanha de Aperfeiçoamento e Difusão do Ensino Secundário (CADES) - Decreto № 34.638 de 17 de novembro de 1953, assinado por Getúlio Vargas e Antônio Balbino". (...) Pinto (2008) identificou quatro momentos distintos na história da CADES: do anúncio à implantação (1953-1956); consolidação e expansão (1956-1963); renovação administrativo-pedagógica (1963-1964); declínio e desaparecimento (1964-1970)". (BARALDI; GAERTNER, 2010).
} 
A perspectiva da equiparação da formação docente ao nível superior, como caminho obrigatório para atuar nas salas de aula, foi um passo importante, mas, aparentemente, ainda manteve os estudantes de licenciatura distantes de uma produção autoral de conhecimento. Além disso, existe o desafio, em âmbito nacional, de integrar todos os futuros professores a uma formação de qualidade e comprometida com as evidências científicas.

Vemos, na sequência, que os desafios ligados à educação em nível secundário continuam sendo um tema na ordem do dia e, mais recentemente, a nova Base Nacional Comum Curricular, que orienta as diretrizes para o ensino básico, desde 2018, também influencia diretamente a formação dos professores. O ponto que observamos é como esse documento dialoga com o perfil dos professores e estudantes de pedagogia e licenciaturas, segundo o último Censo da Educação Superior 2019 realizado pelo INEP.

\section{Um retrato dos professores e sua formação}

As correntes pedagógicas que orientam as diretrizes educacionais a partir da LDB no 9.304/1996 têm uma relação próxima com o ideário da Escola Nova dos anos de 1930. Isso significa que os estudos pedagógicos se concentraram nas diferentes ciências aplicadas que auxiliam na produção de metodologias de aprendizagem mais eficazes.

Desta forma, os cursos de pedagogia e as respectivas licenciaturas direcionaram seus currículos para uma formação mais técnica dos futuros professores ${ }^{12}$. Isso se revela pela organização da oferta desses cursos, nas instituições que os oferecem e no percurso formativo estabelecido. Esse retrato é representado pelos dados do último Censo da Educação Superior realizado pelo Inep em 2019.

O Brasil possui um número significativo de instituições de ensino superior, contando com 2.608 estabelecimentos, sendo a grande maioria pertencente a iniciativa privada, com 2.306 , ou seja $88,5 \%$ da oferta. O censo revela que dos anos de 2014 a 2019 a oferta de educação à distância teve um aumento de $45 \%$, enquanto o ensino presencial encolheu

\footnotetext{
12 "As influências da teoria de Piaget destituíram o professor de seu papel como transmissor do conhecimento. Esse fato foi observado por Imbernón Muñoz (2013), que defende a ideia de que a formação dos professores se converteu, durante muito tempo, em encontrar soluções aos problemas técnicos do ensino como: registrar programações em tabelas, avaliar e qualificar, desenvolver metodologias determinadas, entre outros, e não em dar respostas às situações problemáticas da cultura do ensinar, de forma a desenvolver os saberes e experiências no contexto curricular, como deveria ser uma formação que permitisse intervir no desenvolvimento curricular". (BRANCO, et al, 2018, p. 63).
} 
$5,2 \%$. No total, a rede privada responde por $75,8 \%$ dos matriculados em cursos superiores no país, sendo a maioria ainda na modalidade presencial representando $65 \%$.

No que diz respeito especificamente à formação de professores, o curso de pedagogia aparece como aquele de maior oferta na modalidade à distância entre as universidades públicas e privadas, aparecendo em segundo lugar na modalidade presencial em universidades públicas e em sexto nas privadas. Em números absolutos, a pedagogia responde por 815.959 matriculados em 2019, assumindo a segunda posição em demanda.

As licenciaturas em geral não aparecem entre os cursos com maior oferta, exceto na modalidade à distância em universidades públicas. O bacharelado ainda representa a grande parte do grau acadêmico almejado pelos estudantes, porém, as licenciaturas aparecem na sequência com 19,7\%, superando o grau de tecnólogo. Além disso, a oferta de cursos de licenciatura é predominantemente da iniciativa privada com $73,5 \%$ dos matriculados e o formato à distância responde por $53,3 \%$.

Ressaltamos também que a pesquisa está longe de ser a prioridade dos estabelecimentos de ensino superior, com ênfase para as instituições privadas. O número de professores com doutorado é de apenas 16,6\%; mestrado 37,5\% e especialização $45,9 \%$, tendo as universidades públicas a maior parte dos professores doutores. Levando em conta que o regime de dedicação exclusiva é o único que garante plena integração entre ensino, pesquisa e extensão, os dados mostram que apenas $29,2 \%$ das universidades privadas contratam por esse regime, em contraposição a $86,2 \%$ nas públicas.

O censo permite observar também a correspondência entre a formação docente e a disciplina lecionada na educação básica. O quadro revela que existe uma discrepância entre as diferentes disciplinas, sendo língua portuguesa a que responde pelo maior índice de correlação entre professores com licenciatura plena ou bacharel com curso de complementação nessa disciplina $(81,4 \%)$. Na sequência aparecem educação física (81,3\%); Biologia (79,9\%); Matemática (74\%); Geografia (73\%); História (72,7\%); Química (60,4\%); Língua Estrangeira (54\%); Artes (51,2\%); Filosofia (48,3\%); Física (45,7\%) e Sociologia (32,2\%). Nas disciplinas com menor índice de correspondência entre a formação adequada e a disciplina de atuação, o professor possui formação em áreas diferentes ou correlatas a que leciona. $O$ documenta ainda ressalta o seguinte:

Pouco mais de 158 mil professores que atuam na educação básica frequentam um curso superior no Brasil. Apenas 32\% desses professores não têm formação 
superior, sugerindo que boa parte deles buscam uma segunda licenciatura. Uma evidência importante e preocupante, é que $25 \%$ desses professores estão frequentando cursos que não são de licenciatura. (BRASIL, 2020, p. 81).

O destaque desses dados revela que as metas do Estado atendem a uma expectativa de universalizar a formação de professores a nível superior, como preconiza a LDB nำ 9.394/1996. Contudo não há menção quanto à qualidade dos cursos ofertados para os docentes que atuarão na educação básica. Assim, demonstramos que as diretrizes estabelecidas pela nova BNCC vêm alterar o lugar do professor e estabelecer uma dinâmica de trabalho que privilegia o desenvolvimento de habilidades e competências, nas quais o docente se torna um mediador entre os saberes e os alunos. A questão é: os professores estão sendo preparados para essas mudanças? A análise a seguir discute essa questão.

\title{
A nova BNCC e o perfil do professor
}

Segundo Meira; Giareta (2020), há uma relação intrínseca entre as reformas educacionais e o sistema econômico vigente. $\mathrm{Na}$ atual conjuntura sócio-política do Brasil, o neoliberalismo é o sistema hegemônico que pauta todas as dimensões da vida privada e pública.

O neoliberalismo tem alterado significativamente as dinâmicas de produção e a caraterística do trabalho. Novas habilidades e competências ${ }^{13}$ têm sido exigidas dos trabalhadores e iniciativas de empreendedorismo crescem cada vez mais. Nesse sentido, a educação passa por transformações que visam atender à essa flexibilização radical no campo do trabalho. Assim aponta Meira; Giareta (2020):

\begin{abstract}
O neoliberalismo exige, assim, um duplo movimento da escola e dos sistemas de ensino. De um lado pauta o aprofundamento da lógica da flexibilização assentada sobre matrizes tecnológicas para dar conta da nova organização estrutural do mundo do trabalho e de outro lado o aprofundamento lógico do controle gerencial em nome da aproximação adaptativa da educação às lógicas ilimitadas de precarização das relações de empregabilidade. (MEIRA; GIARETA, 2020, p. 116).
\end{abstract}

\footnotetext{
${ }^{13}$ A nova BNCC assim define Habilidades e Competências: "Na BNCC, competência é definida como a mobilização de conhecimentos (conceitos e procedimentos), habilidades (práticas, cognitivas e socioemocionais), atitudes e valores para resolver demandas complexas da vida cotidiana, do pleno exercício da cidadania e do mundo do trabalho". (BRASIL, 2017, p. 8). No mercado de trabalho mais competitivo, os trabalhadores necessitam valorizar sua força de trabalho com cada vez mais recursos para execução de múltiplas tarefas que, muitas vezes, excede sua formação e atividades inicialmente designadas.
} 
Com o objetivo de se aproximar das demandas do mercado de trabalho, na linguagem neoliberal, a nova $\mathrm{BNCC}^{14}$ orienta algumas diretrizes consideradas inovadoras para a educação básica. Dentre as mudanças que impactam a atuação do professor, de maneira particular no ensino médio, destacamos a organização curricular pautada pela interdisciplinaridade, sobretudo pela divisão por áreas do conhecimento e não mais por disciplinas; o desenvolvimento de habilidades e competências; a formação integral e o incentivo a metodologias diversificadas de ensino ${ }^{15}$.

Para esta análise, pautamos as metodologias diversificadas que, em nosso entendimento, resgatam o conceito de metodologias ativas presente no ideário da Escola Nova nos anos de $1930 .{ }^{16}$ O ponto que discutimos diz respeito ao fato de que as metodologias ativas atribuem ao professor o papel de mediador entre os alunos e alunas e os saberes a serem aprendidos. A discussão é que talvez a formação de professores atualmente não consiga atender a essa última diretriz da nova BNCC.

\section{O professor mediador}

Os embates educacionais ocorridos no Brasil na década de 1930 colocavam duas tendências pedagógicas em disputa: os tradicionalistas e os renovadores. A educação tradicional estabelece sua pedagogia centrada nos professores. Pela transmissão verbal de conhecimentos, o professor espera uma postura passiva e disciplinada dos alunos. Ao professor cabe transmitir conteúdos e verificar o aprendizado por meio de provas. Os renovadores criticavam esse modelo, pois em sua visão os alunos e alunas deveriam ocupar o lugar de centralidade na prática pedagógica. A maturidade cognitiva e os

\footnotetext{
${ }^{14}$ A nova LDB foi ratificada pela Lei 13.415/2017 e foi fruto de um debate em torno da consolidação de um Sistema Nacional de Educação (SNE). "Nesse sentido, a Base Nacional Comum Curricular está sendo apresentada como o alicerce para a renovação e o aprimoramento da educação básica como um todo, assumindo um forte sentido estratégico nas ações de todos os educadores, bem como gestores de educação no Brasil. (BRANCO [et al.], 2018, p. 100).

15 "Selecionar e aplicar metodologias e estratégias didático-pedagógicas diversificadas, recorrendo a ritmos diferenciados e a conteúdos complementares, se necessário, para trabalhar com as necessidades de diferentes grupos de alunos, suas famílias e cultura de origem, suas comunidades, seus grupos de socialização etc." (BRASIL, 2017, p. 17).

16 O próprio documento da BNCC destaca certa filiação com o movimento dos pioneiros da Escola Nova em uma nota de rodapé: "Na história educacional brasileira, as primeiras referências à educação integral remontam à década de 1930, incorporadas ao movimento dos Pioneiros da Educação Nova e em outras correntes políticas da época, nem sempre com o mesmo entendimento sobre o seu significado". (BRASIL, 2017, p. 14).
} 
interesses das crianças e adolescentes deveriam ser o ponto de partida para a construção do currículo e às escolhas metodológicas de aprendizagem.

Essa crítica à pedagogia tradicional ganha ainda mais força a partir dos anos de 1960, por meio dos trabalhos de Paulo Freire na alfabetização de adultos (FREIRE, 2020). Mesmo após o golpe de 1964 e o exílio de Freire, suas ideias pedagógicas se mantiveram vivas e hoje Paulo Freire é o patrono da educação no Brasil.

A partir das práticas, junto a comunidades rurais, de alfabetização de adultos, registrado no livro Educação como Prática da Liberdade, Freire desenvolve um método pautado pelo diálogo, palavra chave em seu processo educativo.

\footnotetext{
Mas como realizar esta educação? Como proporcionar ao homem meios de superar suas atitudes, mágicas ou ingênuas, diante de sua realidade?

Como ajudá-lo a criar, se analfabeto, sua montagem de sinais gráficos? Como ajudá-lo a inserir-se?

A resposta nos parecia estar: a) num método ativo, dialogal, crítico e criticizador; b) na modificação do conteúdo programático da educação; c) no uso de técnicas como a da redução e da codificação.

Somente um método ativo, dialogal, participante, poderia fazê-lo. (FREIRE, 2020, p. 141).
}

O desenvolvimento de um método ativo e dialogal necessita da criação de um espaço pedagógico democrático que permita a construção de conhecimentos. $\mathrm{Na}$ experiência descrita por Freire, a realidade das comunidades era o fundamento das "palavras geradoras" que davam início ao processo de alfabetização. De forma correlata, a BNCC, a partir de seus documentos e pedagogias de referência, orienta metodologias ativas nas quais os alunos e alunas sejam protagonistas e seus conhecimentos prévios sejam valorizados.

O desenvolvimento de um método ativo e dialogal necessita da criação de um espaço pedagógico democrático que permita a construção de conhecimentos. $\mathrm{Na}$ experiência descrita por Freire, a realidade das comunidades era o fundamento das "palavras geradoras" que davam início ao processo de alfabetização. De forma correlata, a BNCC, a partir de seus documentos e pedagogias de referência, orienta metodologias ativas nas quais os alunos e alunas sejam protagonistas e seus conhecimentos prévios sejam valorizados.

A problemática apresentada indica uma mudança quanto ao papel do professor, uma vez que o conhecimento do estudante é o ponto de partida para a construção de novos saberes. Assim, cabe ao professor ser o responsável por criar um espaço de produção de 
conhecimento no qual: "quem forma se forma e re-forma ao formar e quem é formado formase e forma ao ser formado". (FREIRE, 2020, p. 25).

Desta forma, para que a escola supere a educação bancária e atenda às novas diretrizes da BNCC, quanto à aplicação de metodologias ativas, o professor precisa ter condições materiais e técnicas para sua aplicação. A construção de conhecimento na educação básica exige rigor metodológico, segundo Freire (2020, p. 28): "Uma de suas tarefas primordiais é trabalhar com os educandos a rigorosidade metódica com que devem se "aproximar" dos objetos "cognoscíveis".

Freire (2020) discute em Pedagogia da Autonomia os caminhos da formação docente em favor da autonomia dos estudantes. Esse trabalho se pauta por saberes e valores que os professores devem adquirir e desenvolver. Nesta obra há uma afirmação que merece destaque: "Não há ensino sem pesquisa e pesquisa sem ensino". Essa citação reafirma toda a argumentação deste artigo. Freire prossegue:

\begin{abstract}
Fala-se hoje, com insistência, no professor pesquisador. No meu entender, o que há de pesquisador no professor não é uma qualidade ou uma forma de ser ou de atuar que se acrescente à de ensinar. Faz parte da natureza da prática docente a indagação, a busca, a pesquisa. $O$ de que se precisa é que, em sua formação permanente, o professor se perceba e se assuma, porque professor, como pesquisador. (FREIRE, 2020, p. 30).
\end{abstract}

O excerto indica que há uma condição natural de pesquisador no professor, entretanto, o que observamos é que essa condição não é natural, mas construída durante a formação, se esta possibilitar caminhos para que isso seja desenvolvido. $O$ retrato feito sobre a formação docente não adentrou o currículo dos cursos de pedagogia e licenciatura, mas os dados apresentados ajudam a visualizar que não há uma prioridade na qual a produção de conhecimento seja parte constitutiva do percurso formativo dos professores.

Nesse sentido, no que diz respeito à orientação da nova BNCC para a aplicação de metodologias ativas no ensino básico, segundo os argumentos do professor Paulo Freire, no tocante à formação de professores, e tendo em vista o histórico da atuação docente que discutimos nesse artigo, no atual cenário apresentado pelo Censo da Educação Superior de 2019, não há indicativos de que esse objetivo da Lei no 13.415/2017 possa ser atingido. O preparo metodológico dos professores para que o ensino se realize num espaço democrático de construção de conhecimento é condição sine qua non para que as metodologias ativas sejam devidamente aplicadas. 


\section{ENSIN@UFMS 2021}

ISSN 2525-7056

\section{Consideração finais}

Este trabalho buscou fazer uma reflexão sobre a orientação da nova BNCC para a aplicação de metodologias diversificadas em sala de aula, propondo o papel de professor mediador, entre os saberes e os estudantes, aos atuais docentes, em diálogo com o retrato da formação de professores atualmente. O estudo contou também com uma perspectiva histórica e comparativa, a partir da observação de que há uma separação no campo da docência entre os professores que produzem conhecimento e os que somente os transmitem. (GERALDI, 2013; FREIRE, 2020).

Para demonstrar esse processo, percorremos a história da formação de professores, com ênfase no ensino secundário, já que no Brasil houve professores que produziam conhecimento enquanto atuavam na educação básica. Esse fenômeno foi abordado pelo estudo da trajetória de dois professores de língua portuguesa que atuaram no Colégio Pedro II, entre os anos de 1930 e 1960, são eles: Antenor Nascentes (1886-1972) e Leodegário Amarantes do Azevedo Filho (1927-2011). A partir disso, seguimos pelas mudanças sócio históricas e legislativas pelas quais passou o ensino básico e a formação de professores até a LDB № 9.394/1996. Esse itinerário mostrou as causas do distanciamento do professor de nível básico da produção de conhecimentos e os prejuízos decorrentes desse processo.

Finalmente, o retrato da formação docente, apresentado pelo Censo do Ensino Superior do INEP, feito em 2019, traz indícios de que essa formação continua distante de priorizar a produção de conhecimento como parte importante do percurso dos futuros professores. Nesse sentido, a orientação da nova BNCC para a aplicação de metodologias diversificadas na sala de aula pode não avançar de forma satisfatória. Sustentamos essa hipótese embasados pela afirmação de Freire (2020) de que "Não há ensino sem pesquisa e pesquisa sem ensino". Diante disso, professores pouco familiarizados com as metodologias cientificas podem apresentar muitas dificuldades para proporcionar espaços de aprendizado adequados a essa orientação da nova BNCC.

\section{Referências bibliográficas}

ARAÚJO, A. M. O legado humanístico de um mestre. Revista da academia brasileira de filologia, 2011, no VIII. 
AZEVEDO. I. S. L. A tentativa de Ihe oferecer uma página. Rio de Janeiro, 2011. Disponível em: http://llp.bibliopolis.info/confluencia/pdf/58.pdf. Acesso em 14 mar. 2021.

AZEVEDO FILHO, L. A. Didática Especial de Português (para o curso secundário). Rio de Janeiro: ed. Conquista, 1958.

BARALDI, I.M.; GAERTNER, R. Contribuições da CADES para a Educação (Matemática) Secundária no Brasil: uma descrição da produção bibliográfica. BOLEMA. Boletim de Educação Matemática (UNESP. Rio Claro. Impresso), v. 23, p. 159-183, 2010.

BAZZO. V. L. Os institutos superiores de educação ontem e hoje. Educ. rev. n.23 Curitiba Jan./ Jun. 2004.

BICCAS. M. S. Reforma Francisco Campos: estratégias de formação de professores e modernização da escola mineira (1927-1930). In: MIGUEL, Maria E. B et al. Reformas Educacionais: as manifestações da Escola Nova no Brasil (1920 a 1946). Campinas, SP: Autores Associados; Uberlândia MG: EDUFU, 2011.

BRANCO, E. P. [et al.]. A implantação da base nacional comum curricular no contexto das políticas neoliberais. Curitiba: Appris, 2018.

BRASIL. Ministério da Educação. Base Nacional Comum Curricular. Brasília, 2017.

BRASIL. Instituto Nacional de Estudos e Pesquisas Educacionais Anísio Teixeira (Inep). Censo da Educação Superior, 2019.

CHARTIER. R. A Ordem dos Livros: leitores, autores e bibliotecas na Europa entre os séculos XIV e XVIII. 2. ed. Brasília: Ed. UnB, 1998.

FÁVERO, L. L. O ensino no império: 1837-1867 - trinta anos do imperial colégio de Pedro II. In: ORLANDI, E. P., GUIMARÃES. E. (orgs.) Institucionalização dos Estudos da

Linguagem: A disciplinarização das ideias linguísticas. Campinas, SP: Pontes, 2002.

FREIRE, P. Pedagogia da Autonomia: saberes necessários à pratica educativa. Rio de Janeiro/ São Paulo: Paz e Terra, 2020.

FREIRE, P. Educação como prática da liberdade. Rio de Janeiro/ São Paulo: Paz e Terra, 2020.

GERALDI, J. W. Portos de Passagem. São Paulo: Editora WMF Martins Fontes, 2013.

HAMPEJS, Z. Três aspectos da obra de Antenor Nascentes. Revista dos cursos de letras. Curitiba-Brasil, n. 12, 1961.

MEIRA, W. S.; GIARETA, P. F. A Mediação Capitalista sobre o Trabalho e as Implicações para a Educação: aproximações teóricas. Colloquium Humanarum. Presidente Prudente. v. 17, jan/dez. 2020, p. $108-118$. 
NASCENTES, A. O idioma nacional na escola secundária. São Paulo: ed. Melhoramentos, 1935;

NONATO, S. Lições de Metodologia de Ensino de Língua Portuguesa: práticas didáticas e formação docente. Tese de livre-docência. Faculdade de Educação, Universidade de São Paulo, 2019. Disponível em:

https://www.teses.usp.br/teses/disponiveis/livredocencia/48/tde-13092019-102606/ptbr.php. Acesso em 15 mar. 2021.

SAVIANI, D. A pedagogia no Brasil: história e teoria. Campinas, SP: Autores Associados, 2012.

SAVIANI, D. História das ideias pedagógicas no Brasil. Campinas, SP: Autores Associados, 2019.

SCHWARCZ, L. M. O espetáculo das raças: cientistas, instituições e questão racial no Brasil - 1870-1930. São Paulo: Companhia das Letras, 1993.

SCHWARCZ, L. M. A Longa viagem da biblioteca dos reis: do terremoto de Lisboa à independência do Brasil. São Paulo: Companhia das Letras, 2002.

SILVA, V. B. Livros que ensinam a ensinar: um estudo sobre os manuais pedagógicos brasileiros (1930-1971). Curitiba: Appris, 2019.

TANURI, L. M. História da formação de professores. Revista Brasileira de Educação. Mai/Jun/Jul/Ago, n. 14, 2000.

VILLELA, H. O. S. Do artesanato à profissão - Representações sobre a institucionalização da formação docente no século XIX. In: STEPHANOU, M.; BASTOS, M. H. C. (orgs.) Histórias e memórias da educação no Brasil, vol. II: século XIX. Petrópolis, RJ: Vozes, 2014.

\section{NOTAS}

IDENTIFICAÇÃO DE AUTORIA

Marco Aurelio Cardoso Moura. Bacharel em Letras. Mestrando na Faculdade de Educação da Universidade de São Paulo, São Paulo, SP. Brasil.

E-mail: marco.aurelio.moura@usp.br

(i) https://orcid.org/0000-0002-9146-848X

\section{AGRADECIMENTOS}

Não se aplica.

\section{FINANCIAMENTO}

Este estudo integra a pesquisa de Mestrado que se vem desenvolvendo no âmbito do Projeto de Pesquisa "Metodologia de Ensino de Língua Portuguesa como disciplina curricular da formação docente: incursões em uma biblioteca de manuais pedagógicos" (CNPQ-Chamada Universal-Processo 438985/2018-4-2019-2020), 
no Programa de Pós-Graduação em Educação da Faculdade de Educação da Universidade de São Paulo, sob orientação do professor Dr. Sandoval Nonato.

\section{CONSENTIMENTO DE USO DE IMAGEM}

Não se aplica.

\section{APROVAÇÃO DE COMITÊ DE ÉTICA EM PESQUISA}

Não se aplica.

\section{LICENÇA DE USO}

Autores mantêm os direitos autorais e concedem à revista ENSIN@ UFMS - ISSN 2525-7056 o direito de primeira publicação, com o trabalho simultaneamente licenciado sob a Licença Creative Commons Attribution (CC BY-NC-SA 4.0), que permite compartilhar e adaptar o trabalho, para fins não comerciais, reconhecendo a autoria do texto e publicação inicial neste periódico, desde que adotem a mesma licença, compartilhar igual.

\section{EDITORES}

Patricia Helena Mirandola Garcia, Eugenia Brunilda Opazo Uribe, Gerson dos Santos Farias.

\section{HISTÓRICO}

Recebido em: 26/03/2021 - Aprovado em: 18/10/2021 - Publicado em: 06/12/2021.

\section{COMO CITAR}

MOURA, M. A. C. A Produção de Conhecimento na Formação de Professores: Uma Condição Indispensável. Revista ENSIN@ UFMS, Três Lagoas, v. 2, n. 6, p. 34-56. 2021. 